\title{
Safety of labour and delivery following closures of obstetric services in small community hospitals
}

\author{
Jennifer A. Hutcheon PhD, Corinne A. Riddell PhD, Erin C. Strumpf PhD, Lily Lee MSN MPH, Sam Harper PhD
}

Cite as: CMAJ 2017 March 20;189:E431-6. doi: 10.1503/cmaj.160461

CMAJ Podcasts: author interview at https://soundcloud.com/cmajpodcasts/160461-res

\begin{abstract}
BACKGROUND: In recent decades, many smaller hospitals in British Columbia, Canada, have stopped providing planned obstetric services. We examined the effect of these service closures on the labour and delivery outcomes of pregnant women living in affected communities.
\end{abstract}

METHODS: We used maternal postal codes to identify delivery records (19982014) of women residing in a community affected by service closure. The records were obtained from the British Columbia Perinatal Data Registry. We examined the effect of the closures using a within-communities fixed-effects framework and included similar-sized communities without service closures to control for underlying time trends. The primary outcome was a previously published composite measure of labour and delivery safety, the Adverse Outcome Index, which includes adverse events such as birth injury and unanticipated operative procedures, and includes weights for severity of adverse events. Secondary outcomes included maternal or newborn transfer, and use of obstetric interventions.

RESULTS: We found little evidence that closure of planned obstetric services affected the risk of composite adverse maternal-newborn outcome $(-0.4$ ex- cess adverse events per 100 deliveries, $95 \%$ confidence interval $[\mathrm{Cl}]-2.0$ to 1.1 ), or most other secondary outcomes. The severity of composite outcome events decreased following the closures (rate ratio $0.58,95 \% \mathrm{Cl} 0.36$ to 0.89 ). Closures were associated with increases in use of epidural analgesia (3.4 excess events per 100 deliveries, $95 \% \mathrm{Cl} 0.4$ to 6.3$)$ and length of antepartum stay $(0.6 \mathrm{~h}, 95 \% \mathrm{Cl}$ 0.1 to $1.0 \mathrm{~h}$ ).

INTERPRETATION: Closure of planned obstetric services in low-volume hospitals was not associated with an increase or decrease in frequency of adverse events during labour and delivery.
$\mathbf{T}$ he safety of obstetric services in small, rural communities remains uncertain. Delivery at hospitals with low delivery volumes has been correlated with better, worse and comparable pregnancy outcomes compared with delivery at larger centres, ${ }^{1-7}$ and studies examining the safety of delivery at rural versus urban hospitals have likewise produced conflicting results. ${ }^{8-12}$

Establishing the relative safety of obstetric care in small rural hospitals is challenging. Studies comparing health outcomes according to hospital delivery volume $\mathrm{e}^{3-5}$ are influenced by underlying referral patterns in which higher rates of adverse outcomes at larger centres may reflect referrals of high-risk women. Adjustment for maternal risk factors is unlikely to completely account for case-mix differences. Comparisons made according to catchment area (in which women are classified according to their place of residence $)^{1,2,4,8-12}$ prevent bias due to referral patterns, but confounding by differences in socioeconomic status and health behaviours between women living in urban and rural areas remains a concern. ${ }^{10}$ Such comparisons also have less utility for decisions about service regionalization because the policy option is not to change rural women's place of residence to an urban setting, but rather to have rural women travel to an urban setting to deliver, which may lead to increased risks, such as unintentional out-of-hospital delivery. ${ }^{2}$

Since 1998, nearly one-third of hospitals in British Columbia, Canada, have stopped providing planned obstetric services. The vast majority of service closures occurred in low-volume hospitals ( $<150$ deliveries/yr) serving smaller, rural communities. In this study, we examined whether the frequency and severity of maternal-neonatal labour and delivery health outcomes of women residing in small communities were affected by the closure of their community hospitals. Other implications of obstetric service provision in small communities (e.g., social, economic), although important, are beyond the scope of this study. 


\section{Methods}

\section{Setting}

Our study population was drawn from deliveries in BC, 19982014. We obtained abstracted medical chart data from the British Columbia Perinatal Data Registry, a quality-controlled database that contains records for more than $99 \%$ of deliveries in the province, including home births. ${ }^{13}$

\section{Study design}

We evaluated the effect of obstetric service closures using a within-community fixed-effects design. ${ }^{14}$ Specifically, we estimated the change in the risk of adverse outcomes within each affected community before and after the closure, akin to including an indicator variable for each community in a regression model. Using each community as its own control holds constant any time-invariant community characteristics ("fixed effects") that are challenging to control for using measured covariates. In estimating these within-community changes, we control for temporal trends in outcomes based on both closure and control communities. These trends capture any changes in risk unrelated to service closures, which would bias a simple pre-post comparison $^{15}$ (Appendix 1, available at www.cmaj.ca/lookup/suppl/ doi:10.1503/cmaj.160461/-/DC1).

We used residential postal codes to identify deliveries to women living in the 25 communities affected by closure of planned obstetric services, based on Statistics Canada census subdivisions (Appendix 2, available at www.cmaj.ca/lookup/ suppl/doi:10.1503/cmaj.160461/-/DC1). This geographically defined cohort therefore included deliveries to all women living in the community irrespective of delivery location (e.g., women living in the community before the closure who delivered elsewhere and women who delivered after the closure of the local hospital's planned obstetric services). We excluded 2 communities because of their proximity to larger metropolitan areas and 2 communities because of uncertainty about the precise dates of service closures. Residential postal codes were also used to identify deliveries to women living in the 12 communities in $\mathrm{BC}$ with low-volume hospitals (<150 annual births) unaffected by obstetric service closures (Appendix 2), used to control for time trends. Appendix 3 (available at www.cmaj.ca/lookup/suppl/doi:10.1503/cmaj. 160461/-/DC1) shows the geographic locations of communities in our study in relation to secondary and tertiary centres.

\section{Outcomes}

Our primary outcome was a previously developed composite of 10 adverse maternal or newborn events, the Adverse Outcome Index. ${ }^{16,17}$ The index was created through an expert consensus process as a tool for assessing the safety of labour and delivery. It measures the occurrence of any of the following: maternal death, intrapartum stillbirth or in-hospital death of a newborn weighing more than $2500 \mathrm{~g}$ and having a gestational age of 37 weeks or greater with no congenital anomalies or fetal hydrops, uterine rupture, maternal admission to the intensive care unit, birth injury, unanticipated operative procedure, neonatal admission to the intensive care unit for a duration greater than 48 hours for newborns weighing more than $2500 \mathrm{~g}$ and having a gestational age of 37 weeks or greater, 5-minute Apgar score less than 7, maternal blood transfusion, or third- or fourth-degree perineal tear. We expanded the definition of "neonatal admission to the intensive care unit" to include transfer within 24 hours of birth to a facility with a neonatal intensive care unit for a newborn weighing more than $2500 \mathrm{~g}$ with a gestational age of 37 weeks or greater. Variables used to calculate the index and provincial temporal trends are detailed elsewhere. ${ }^{18,19}$

We also calculated a weighted Adverse Outcome Index, using previously published weights derived through a consensus process by obstetricians and nurses on the American College of Obstetricians and Gynecologists Committee on Patient Safety and Quality Improvement. The weights account for the severity of different components in the composite (750 points for maternal death, 400 points for uterine rupture, 100 points for maternal admission to the intensive care unit, 65 points for birth trauma, 40 points for unanticipated operative procedure, 35 points for neonatal admission to the intensive care unit, 25 points for 5-minute Apgar score $<7,20$ points for blood transfusion, and 5 points for third- or fourth-degree tear). ${ }^{16}$ We further examined an (equally weighted) secondary outcome consisting of the most serious components of the index: in-hospital maternal or perinatal death, uterine rupture or maternal admission to the intensive care unit. ${ }^{19}$

Other secondary outcomes were as follows: maternal or newborn transfer to a secondary or tertiary care hospital, maternal admission-to-delivery interval (hours), mode of delivery (cesarean, instrumental delivery), use of obstetric interventions (epidural, labour induction, labour augmentation) and out-ofhospital birth (planned or unplanned).

\section{Statistical analyses}

We compared communities with and without a closure by calculating medians with interquartile ranges or counts with proportions of the annual 1998 delivery volume, distance to next closest hospital with planned obstetric services, and Rural Birth Index (a tool that estimates the appropriate level of obstetric service provision for a given rural community). The Rural Birth Index combines information on 3 key characteristics for predicting sustainability of rural service: population birth numbers, social vulnerability and geographic isolation. A higher value indicates the need for a more specialized level of care, ranging from 0-7 (maternity service level A: no local intrapartum services) and 7-9 (service level B: local intrapartum services without operative delivery) to greater than 27 (service level E: specialist only models). ${ }^{20}$ The percentage of women delivering at their local hospital was calculated as the number of women delivering at their community hospital divided by the total number of deliveries to women residing in that community.

We estimated the change in probability of an adverse outcome associated with service closure using a within-community fixed-effects linear probability model with robust standard errors clustered at the community level. We focused our interpretation on the absolute scale (i.e., adverse events per 100 deliveries), which is more relevant than relative risks for assessing the population burden or benefit of the policy change. ${ }^{21}$ We examined 
median rather than mean maternal antepartum length of stay (in hours) because of its highly skewed distribution. Conditional fixed-effects Poisson regression was used to estimate relative measures of effect (incidence rate ratios [IRR]). Calendar time was modelled as a linear term or a restricted cubic spline with 3, 4 or 5 knots, and the final fit was chosen as the approach that provided the best model fit for the control and preclosure data (using the Akaike information criterion). We did not adjust for maternal characteristics such as pre-pregnancy body mass index or parity, because we found no evidence that these characteristics changed concurrently with service closure.

To estimate the effect of closure on the weighted Adverse Outcome Index we used a fixed-effects Poisson regression model, in which the total count of severity points associated with an adverse event was modelled as the outcome. Confidence intervals for IRRs were estimated through bootstrapping with 1000 samples. We compared the IRRs produced by a severityweighted model with IRRs from a fixed-effects Poisson model where the adverse outcome was not weighted for event severity. Analyses were conducted using Stata 13.

\section{Sample size estimation}

Conservatively assuming a fixed sample size of 3810 deliveries in the 3 years before and after closure (based on 1998 delivery volumes in affected hospitals), and an Adverse Outcome Index rate of $7 \%,{ }^{18}$ we estimated that we would have $80 \%$ power to detect a risk ratio of 0.7 before versus after closure (although we hypothesized that closures could either increase or decrease risks).

\section{Ethics approval}

The University of British Columbia/Children's and Women's Health Centre of British Columbia Research Ethics Board approved this study (H15-02026).

\section{Results}

Our cohort included 20874 deliveries to women residing in a community that experienced a closure of planned obstetric services $(n=$ 11949) or a similar-sized community without service closure $(n=$ 8925). Among women residing in a community affected by a service closure, 5796 deliveries (48.5\%) occurred before the closure.

Compared with communities without service closures, communities with closures performed 19 fewer deliveries per year in 1998 and were $28 \mathrm{~km}$ (14 min) closer to the next community with planned obstetric services (Table 1). There were no differences in the median Rural Birth Index classifications, which corresponded to a service level B (scores of 7-9), or "local intrapartum services without operative delivery." The proportion of women delivering at their local hospital was 7 percentage points higher in communities without a closure compared with the preclosure rate in affected communities (57\% v. $50 \%$, respectively). The small fraction of women $(3 \%, n=169)$ delivering at their local hospital following service closure reflects provision of emergency rather than planned obstetric services. There were no meaningful differences in the pregnancy characteristics of women living in communities with versus without closures, nor pre- versus postclosure within communities experiencing a closure (Table 1).

Table 1: Characteristics of hospitals and pregnancies in communities with and without closures of local planned obstetric services in British Columbia, 1998-2014

Median (IQR) or no. (\%)

\section{Characteristic}

\section{Hospital}

No. of hospitals

Annual 1998 delivery volume*

$48(26-84)$

$107(64-148)$

$72(58-102)$

$8(8-10)$

Rural Birth Index score

\section{Pregnancy}

No. of deliveries

Delivery at local hospital

Maternal age, yr

Nulliparity

Pre-pregnancy BMI†

Birthweight, g

Gestational age at delivery, wk

\section{Communities without closures}

Communities with closures

Note: $\mathrm{BMI}=$ body mass index, $\mathrm{IQR}=$ interquartile range.

*1999 data used for Fort Nelson because data were not available before this point.

†Among 11003 women with available values (53\%; 6219 and 4784 in communities with and without closures, respectively). 
The proportion of women delivering at their local hospital decreased over time in both affected and control communities. In communities without closures, $73.9 \%$ of women delivered at their local hospital in 1998; by 2014, the proportion was $51.6 \%$. After accounting for this time trend, the mean estimated change associated with closure was a decrease of 20 percentage points (95\% Cl -11 to -28$)$. Less than $57 \%$ of women delivered at their local hospital, even before the closure of local obstetric services, as well as in control communities (Table 1).

We found that closure of planned obstetric services was not associated with a significant increase or decrease in risk of adverse events in the Adverse Outcome Index ( -0.4 excess adverse events per 100 deliveries, $95 \% \mathrm{Cl}-2.0$ to 1.1 ), or in the risk of the more severe components of the index (Table 2). Likewise, closures were not significantly associated with changes in risks of maternal or newborn transfer, mode of delivery, labour induction, labour augmentation or out-of-hospital birth. There were small increases in antepartum stay ( $0.6 \mathrm{~h}, 95 \% \mathrm{Cl} 0.1$ to $1.0 \mathrm{~h}$ ) and use of epidural analgesia (3.4 per 100 deliveries, $95 \% \mathrm{Cl} 0.4$ to 6.3 ) following service closure.

When all components of the Adverse Outcome Index were weighted equally, the IRR associated with service closures was 0.94 (95\% Cl 0.74 to 1.18$)$. However, the severity-weighted rate ratio indicated a protective effect of hospital closure (IRR 0.58, $95 \% \mathrm{Cl} 0.36$ to 0.89 ) (i.e., the adverse events that did occur following the service closure were, on average, less severe). We did not conduct further statistical testing to evaluate differences between groups in the index subcomponents owing to the small numbers of each adverse event (Table 3).

\section{Interpretation}

In this study, closure of planned obstetric services in 21 communities in BC did not affect the frequency of adverse outcomes or serious adverse outcomes during labour and delivery. We found that more than $40 \%$ of women in these communities were delivering elsewhere even before the closure of local planned obstetric services (as well as in control communities). With many women already delivering elsewhere, this may partially explain the lack of an overall effect on labour and delivery outcomes following local service closures. However, we estimated that the severity of adverse events decreased after closures. Because of the small number of each adverse event in the composite, it is challenging to determine which specific components were responsible for this decrease, independent of underlying time trends.

Service closures were associated with increased use of epidural analgesia and median length of antepartum stay. We speculate that the increase in use of epidural analgesia reflects increased access to anesthesia services in larger centres, whereas the longer antepartum stay could reflect altered admission thresholds given longer driving times to return home.

The abrupt closure of obstetric units in Philadelphia, Pennsylvania, has previously been evaluated. ${ }^{22-24}$ Zhang and colleagues ${ }^{24}$ found that the closures were associated with a substantial increase in neonatal birth injuries, with increases most pronounced among mothers living in communities with closures. Allen and colleagues ${ }^{25}$ compared time trends of iatrogenic preterm delivery, fetal growth restriction and perinatal mortality in regions of Nova Scotia, Canada,

Table 2: Risk of adverse pregnancy outcomes before and after closure of local planned obstetric services in British Columbia, 1998-2014

\begin{tabular}{|c|c|c|c|c|c|}
\hline \multirow[b]{2}{*}{ Outcome } & \multicolumn{3}{|c|}{ No. $(\text { risk per } 100)^{\star}$} & \multicolumn{2}{|c|}{ Estimated effect of closure } \\
\hline & $\begin{array}{l}\text { Communities } \\
\text { without closures }\end{array}$ & $\begin{array}{l}\text { Communities } \\
\text { with closures } \\
\text { (preclosure) }\end{array}$ & $\begin{array}{l}\text { Communities } \\
\text { with closures } \\
\text { (postclosure) }\end{array}$ & $\begin{array}{l}\text { Incidence rate ratio } \\
(95 \% \mathrm{Cl})\end{array}$ & $\begin{array}{c}\text { Excess adverse } \\
\text { events per } 100 \\
\text { deliveries }(95 \% \mathrm{Cl})^{*}\end{array}$ \\
\hline No. of deliveries & 8925 & 5796 & 6153 & & \\
\hline Adverse Outcome Index & $546(6.1)$ & $379(6.5)$ & $372(6.0)$ & $0.9(0.7$ to 1.2$)$ & $-0.4(-2.0$ to 1.1$)$ \\
\hline Maternal transfer & $117(1.3)$ & $58(1.0)$ & $55(0.9)$ & 1.1 (0.6 to 1.9$)$ & $0.1(-0.5$ to 0.7$)$ \\
\hline Neonatal transfer & $186(2.1)$ & $99(1.7)$ & $109(1.8)$ & 1.4 (0.9 to 2.0$)$ & $0.6(-0.2$ to 1.3$)$ \\
\hline $\begin{array}{l}\text { Maternal antepartum length of } \\
\text { stay, median (IQR), h }\end{array}$ & $5.1(2.3-11.6)$ & $5.7(2.5-12.4)$ & $5.7(2.5-11.8)$ & - & $0.6(0.1$ to 1.0$) \ddagger$ \\
\hline Labour induction & $1776(19.9)$ & $1125(19.4)$ & $1417(23.0)$ & 1.1 (0.97 to 1.3$)$ & $2.4(-0.4$ to 5.1$)$ \\
\hline Labour augmentation & $3089(34.6)$ & $2100(36.2)$ & $2436(39.6)$ & 1.1 (0.99 to 1.2$)$ & $2.3(-0.01$ to 4.7$)$ \\
\hline Out-of-hospital birth & 309 (3.5) & $30(0.5)$ & $109(1.8)$ & $1.9(0.6$ to 6.0$)$ & $0.1(-1.5$ to 1.7$)$ \\
\hline
\end{tabular}


that were affected to varying degrees by hospital closures. They found no consistent evidence that outcomes were worse in regions with more closures, although effects of closures could have been difficult to detect in overall comparisons of regions. ${ }^{25}$

Numerous studies have evaluated the relative safety of smaller hospitals by comparing maternal and newborn outcomes according to the residence of mothers. . $^{1,2,9,10,12}$ However, this approach is prone to confounding from unmeasured differences in the risk profiles of women who live in smaller versus larger communities. In our study, we overcame this concern by using communities as their own controls. Our access to population-based postal code information and use of a methodologically rigorous design allowed us to isolate the effect of the closure from underlying time trends in adverse outcomes. Finally, our medical chart-based data allowed us to examine clinically detailed outcomes most affected by intrapartum care (instead of outcomes such as preterm birth or perinatal death, which, although important public health indicators, may be less sensitive to care during labour and delivery).

\section{Limitations}

Drawing causal conclusions from the within-community fixedeffects design relies on the assumption that, conditional on the estimated time trends, no other changes occurred at the time of the service closure that could also have influenced outcomes. ${ }^{15}$ The design also assumes that changes in adverse outcomes over time in the communities with and without closures are reasonably similar. We found no evidence to invalidate this assumption, but year-to-year variability in rates based on relatively small numbers limited our ability to compare preclosure trends. The severe outcomes we examined were rare, and we were likely underpowered to detect small to moderate (but still important) effects of the closures for these secondary outcomes. The weights used in our severity-weighted outcome reflect expert opinion only, and as a result, the clinical and public health relevance of these analyses are highly dependent on the extent to which the weights reflect the values of local women and care providers.

\section{Conclusion}

The frequency of adverse events during labour and delivery was not significantly higher or lower following closure of planned obstetric services in low-volume hospitals.

Decisions on closure of obstetric services in small communities are complex, and our study provides evidence on clinical outcomes only. Closures have other important consequences for communities, women and families. Rural women without access to local maternity services are 7 times more likely to experience moderate to severe delivery-related stress than women with local services. ${ }^{26}$ Financial issues (e.g., costs of relocating before delivery, travel expenses) as well as lack of continuity of care were identified as reasons. ${ }^{26}$ Lack of a local hospital creates anxiety because of poor winter road conditions while travelling to the hospital for delivery and returning with a newborn postpartum. ${ }^{27}$

Table 3: Adverse Outcome Index components before and after closure of local planned obstetric services in British Columbia, 1998-2014

No. (risk per 100$)^{\star}$

\begin{tabular}{|c|c|c|c|c|}
\hline Adverse Outcome Index component & $\begin{array}{l}\text { Severity points } \\
\text { per adverse event }\end{array}$ & $\begin{array}{l}\text { Communities } \\
\text { without closures }\end{array}$ & Preclosure & Postclosure \\
\hline No. of deliveries & & 8925 & 5796 & 6153 \\
\hline \multicolumn{5}{|l|}{ Maternal } \\
\hline Maternal death $\uparrow$ & 750 & $<5(<0.06)$ & $<5(<0.09)$ & $<5(<0.08)$ \\
\hline Uterine rupture $\dagger$ & 100 & $9(0.10)$ & $<5(<0.09)$ & $5(0.08)$ \\
\hline Maternal ICU admission $†$ & 65 & $<5(<0.06)$ & $<5(<0.09)$ & $<5(<0.08)$ \\
\hline Unanticipated operative procedure & 40 & $57(0.64)$ & $74(1.28)$ & $70(1.14)$ \\
\hline Blood transfusion & 20 & $74(0.83)$ & $53(0.91)$ & $46(0.75)$ \\
\hline Third- or fourth-degree perineal tear & 5 & $208(2.33)$ & $136(2.35)$ & $174(2.83)$ \\
\hline \multicolumn{5}{|l|}{ Fetal/neonatal } \\
\hline $\begin{array}{l}\text { Intrapartum stillbirth or in-hospital death of newborn } \\
\geq 2500 \text { g with no congenital anomalies or fetal hydrops }\end{array}$ & 400 & $15(0.17)$ & $11(0.19)$ & $<5(<0.08)$ \\
\hline Birth trauma & 60 & $24(0.27)$ & $22(0.38)$ & $12(0.20)$ \\
\hline $\begin{array}{l}\text { Neonatal ICU admission }>2 \mathrm{~d} \text { or transfer within } 24 \mathrm{~h} \text { of birth } \\
\text { to a facility with an ICU for newborn } \geq 2500 \mathrm{~g}\end{array}$ & 35 & $76(0.85)$ & $68(1.17)$ & $28(0.46)$ \\
\hline 5-minute Apgar score $<7$ & 25 & $149(1.67)$ & $71(1.22)$ & $85(1.38)$ \\
\hline Weighted Adverse Outcome Score, mean $\ddagger$ & & 2.19 & 2.69 & 1.67 \\
\hline $\begin{array}{l}\text { Note: ICU = intensive care unit. } \\
\text { *Unless stated otherwise. } \\
\text { tCells with }<5 \text { adverse events suppressed for confidentiality. } \\
\text { †Total severity points/number of deliveries. }\end{array}$ & & & & \\
\hline
\end{tabular}


Travel for parous women often requires separation from older children and difficulties in arrangement of child care. ${ }^{27}$ These considerations, informed by other research, must all be weighed when making decisions on closures of planned obstetric services.

\section{References}

1. Finnström O, Berg G, Norman A, et al. Size of delivery unit and neonatal outcome in Sweden. A catchment area analysis. Acta Obstet Gynecol Scand 2006; 85:63-7.

2. Hemminki E, Heino A, Gissler M. Should births be centralised in higher level hospitals? Experiences from regionalised health care in Finland. BJOG 2011; 118:1186-95.

3. Kyser KL, Lu X, Santillan DA, et al. The association between hospital obstetrical volume and maternal postpartum complications. Am J Obstet Gynecol 2012; 207:42.e1-17.

4. Moster D, Lie RT, Markestad T. Neonatal mortality rates in communities with small maternity units compared with those having larger maternity units. BJOG 2001;108:904-9.

5. Rosenblatt RA, Reinken J, Shoemack P. Is obstetrics safe in small hospitals? Evidence from New Zealand's regionalised perinatal system. Lancet 1985; 2:429-32.

6. Kozhimannil KB, Hung P, Prasad S, et al. Birth volume and the quality of obstetric care in rural hospitals. J Rural Health 2014;30:335-43.

7. Kozhimannil KB, Thao V, Hung P, et al. Association between hospital birth volume and maternal morbidity among low-risk pregnancies in rural, urban, and teaching hospitals in the United States. Am J Perinatol 2016;33:590-9.

8. Black DP, Fyfe IM. The safety of obstetric services in small communities in northern Ontario. Can Med Assoc J 1984;130:571-6.

9. Haraldsdottir S, Gudmundsson S, Bjarnadottir RI, et al. Maternal geographic residence, local health service supply and birth outcomes. Acta Obstet Gynecol Scand 2015;94:156-64.

10. Luo ZC, Wilkins R. Degree of rural isolation and birth outcomes. Paediatr Perinat Epidemiol 2008;22:341-9.

11. Nesbitt TS, Connell FA, Hart LG, et al. Access to obstetric care in rural areas: effect on birth outcomes. Am J Public Health 1990;80:814-8.

12. Grzybowski S, Fahey J, Lai B, et al. The safety of Canadian rural maternity services: a multi-jurisdictional cohort analysis. BMC Health Serv Res 2015;15:410.

13. Frosst G, Hutcheon J, Joseph KS, et al. Validating the British Columbia Perinatal Data Registry: a chart re-abstraction study. BMC Pregnancy Childbirth 2015;15:123.

14. Gertler PJ, Martinez S, Premand P, et al. Impact evaluation in practice. Washington (DC): World Bank; 2010.

15. Grimshaw J, Campbell M, Eccles M, et al. Experimental and quasi-experimental designs for evaluating guideline implementation strategies. Fam Pract 2000; 17(Suppl 1):S11-6.

16. Mann S, Pratt S, Gluck $P$, et al. Assessing quality obstetrical care: development of standardized measures. Jt Comm J Qual Patient Saf 2006;32:497-505.

17. Nielsen PE, Goldman MB, Mann S, et al. Effects of teamwork training on adverse outcomes and process of care in labor and delivery: a randomized controlled trial. Obstet Gynecol 2007;109:48-55.

18. Hutcheon JA, Lee L, Joseph KS, et al. Feasibility of implementing a standardized clinical performance indicator to evaluate the quality of obstetrical care in British Columbia. Matern Child Health J 2015;19:2688-97.

19. Perinatal Health Report: deliveries in British Columbia 2014/15. Vancouver: Perinatal Services BC; 2016. Available: www.perinatalservicesbc.ca/Documents/Data -Surveillance/Reports/PHR/PHR_BC_2014_15.pdf (accessed 2016 June 21).
20. Grzybowski S, Kornelsen J, Schuurman N. Planning the optimal level of local maternity service for small rural communities: a systems study in British Columbia. Health Policy 2009;92:149-57.

21. Gigerenzer G, Edwards A. Simple tools for understanding risks: from innumeracy to insight. BMJ 2003;327:741-4.

22. Lorch SA, Martin AE, Ranade R, et al. Lessons for providers and hospitals from Philadelphia's obstetric services closures and consolidations, 1997-2012. Health Aff(Millwood) 2014;33:2162-9.

23. Lorch SA, Srinivas SK, Ahlberg C, et al. The impact of obstetric unit closures on maternal and infant pregnancy outcomes. Health Serv Res 2013;48:455-75.

24. Zhang J, Small DS, Lorch S, et al. Using split samples and evidence factors in an observational study of neonatal outcomes. J Am Stat Assoc 2011;106: 511-24.

25. Allen VM, Jilwah N, Joseph KS, et al. The influence of hospital closures in Nova Scotia on perinatal outcomes. J Obstet Gynaecol Can 2004;26:1077-85.

26. Kornelsen J, Stoll K, Grzybowski S. Stress and anxiety associated with lack of access to maternity services for rural parturient women. Aust J Rural Health 2011;19:9-14.

27. Kornelsen J, Grzybowski S. The reality of resistance: the experiences of rural parturient women. J Midwifery Womens Health 2006;51:260-5.

\section{Competing interests: None declared.}

This article has been peer reviewed.

Accepted: July 12, 2016

Early release: Nov. 7, 2016

Affiliations: Department of Obstetrics and Gynaecology (Hutcheon), University of British Columbia; Perinatal Services BC (Hutcheon, Lee), Vancouver, BC; Department of Epidemiology, Biostatistics and Occupational Health (Riddell, Strumpf, Harper) and Department of Economics (Strumpf), McGill University, Montréal, Que.

Contributors: Jennifer Hutcheon and Lily Lee conceived the research question and selected the study outcomes. Jennifer Hutcheon, Corinne Riddell, Erin Strumpf and Sam Harper developed the analytic approach. All authors contributed to the interpretation of results. Jennifer Hutcheon drafted the manuscript, which the other authors revised for intellectual content. All of the authors approved the final version and agreed to act as guarantors of the work.

Funding: Jennifer Hutcheon holds new investigator awards from the Canadian Institutes of Health Research (CIHR) and the Michael Smith Foundation for Health Research. Corinne Riddell was supported by a CIHR Doctoral Research Award and a CIHR Interdisciplinary Capacity Enhanced Team Grant (no. HOA-80072). Erin Strumpf and Sam Harper are supported by Chercheur boursier Junior 2 awards from the Fonds de recherche du Québec - Santé.

Acknowledgement: The authors thank Julia McGarry for her excellent assistance with data collection.

Correspondence to: Jennifer Hutcheon, jhutcheon@cfri.ca 